\title{
TRTakadeMi
}

ISSN 2149-9446 | Cilt 06 | Sayı 12 | Mayıs 2021 | Dijital Hayat ve Etik

\section{Dijital Refahın Etiği: Multidisipliner Bir Perspektif}

Ethics of Digital Well-Being: A Multidisciplinary Perspective

Christopher Burr ve Luciano Floridi (ed.) (2020)

İsviçre: Springer, 265 Sayfa,

ISBN: 978-3-030-50584-4

\section{Eyüp Engin KÜçüK*}

Dijital refah, yapay zekâ teknolojilerin hayatımızdaki yerinin gittikçe genişlemesiyle beraber bu teknolojinin bütün taraflarını yakından ilgilendiren bir meseleye dönüşmeye başlamıştır. Dijital teknolojilerin tasarımları ve çalışma prensipleri, bireysel ve toplumsal ölçekte büyük etkilere sahip araçlara dönüştükçe bu teknolojilerle kurduğumuz ilişkinin doğasını düşünme ihtiyacı kendisini hissettirmeye başlamıştır. Bu yazıda, akademide son yıllarda yerini almaya başlayan bu konuyla ilgili 2020 yılında okuyucuya sunulan ve farklı alanlarda çalışan akademisyenlere ait 11 makalenin yer aldığı The Ethics of Digital Well-Being: A Multidisciplinary Perspective (Dijital Refahın Etiği: Multidisipliner Bir Perspektif) kitabı değerlendirilecektir.

Kitabın editörlerinden Christopher Burr, bilişsel bilim ve yapay zekâ felsefesi üzerine Alan Turing Enstitüsü ve Oxford Üniversitesi Dijital Etik Laboratuvarında çalışmalarını yürütmektedir. Büyük veri ve yapay zekânın etik ve epistemolojik etkileri üzerine doktora çalışmasını 2020 yılında Bristol Üniversitesinde tamamlayan Burr, hâlihazırda veri temelli teknolojilerle irtibatlı etik problemler üzerine çalışmaktadır. Kitabın diğer editörü olan Luciano Floridi ise Oxford Üniversitesi Enformasyon Etiği ve Felsefe bölümünde profesör olarak görev yapmaktadır. Aynı zamanda Oxford Üniversitesi Dijital Etik Laboratuvarı direktörüdür. Avrupa Komisyonu, Alman Etik Kurulu ve Lordlar Kamarası gibi birçok kurumda diji-

* Boğaziçi Üniversitesi Sosyal Bilimler Enstitüsü Felsefe Anabilim Dalı Yüksek Lisans Programı Mezunu, eyupengink@gmail.com, orcid: 0000-0003-3459-3871 DOI: 10.37679/trta.945292 
tal etik üzerine çalışmış olan Floridi, literatürde The Philosophy of Information (Enformasyon Felsefesi), The Ethics of Information (Enformasyon Etiği) ve The Logic of Information (Enformasyon Mantığı) kitaplarıyla tanınmaktadır.

İlk bölüm, kitabın editörleri Christopher Burr ve Luciano Floridi tarafindan giriş mahiyetinde yazılmış olan ve kitapla aynı başlığı taşıyan "Dijital Refahın Etiği: Multidisipliner Bir Perspektif" bölümüdür. Yazarların bu bölümü yazmadaki temel hedefi kitabın genel amacını ortaya koymak, kitabı oluşturan makalelerde okurun karşılaşacağı farklı yaklaşımlara ve kitabın tartışmayı hedeflediği üç genel temaya dair bir giriş sunmaktır. Bu minvalde giriş kısmında dijital öncelikle felsefe, psikoloji, ekonomi ve sağlık disiplinlerinin dijital refah konusuna dair temel yaklaşımları sunulmakta, sonrasında kitabın genel teması minnettarlık, otomatize müdahaleler ve sürdürebilir ortak refah ele alınmaktadır.

Yazarların ifade ettiği şekliyle kitabın gayesi, dijital refahı temel konulara dair odak noktasını kaybetmeden olabildiğince geniş ve multidisipliner bir perspektif içinde tetkik etmektir. Daha önce belirtildiği gibi giriş bölümünde ise kitaptaki 11 makaleye dair tasvir edici ve bilgilendirici bir giriş sunulmuştur. Burr ve Floridi, giriş bölümünün tamamında sarih bir dil kullanarak kitaplarının amacını net bir şekilde ortaya koymaktadırlar. Farklı disiplinlerin dijital refaha dair teorilerinin ve perspektiflerinin sunumu ve ana temaların izahı, konuya belirli bir disiplinden yaklaşan veya dijital refah konusuna dair öncesinde bilgi sahibi olmayan okuyucular için ciddi bir kolaylık sunmaktadır. Yazarlar detay tartışmalara girmeden konuları giriş seviyesinde betimleyerek kitaptaki hangi makalenin hangi konuyu ele aldığına dair de bilgilendirmede bulunmaktadır. Bu sebeple giriş bölümü özellikle bu alanda ilk defa okuma yapanlar için kolaylaştırıcı bir işlev görmektedir.

Kitabın ikinci bölümü Rafael A. Calvo, Dorian Peters, Karina Vold ve Richard M.Ryan tarafindan yazılan "Yapay Zekâ Sistemlerinde İnsan Özerkliğini Desteklemek: Etik İnceleme İçin Bir Çerçeve" (Supporting Human Autonomy in AI Systems: A Framework for Ethical Enquiry) makalesine ayrılmış. Bu makalenin temel amacı, yapay zekâ sistemlerinin tasarımının ve işleyişinin özerklik ile olan ilişkisine dair bir analiz sunmaktır. Kitabın Charlie Harry Smith tarafindan yazılan üçüncü makalesi "Şirketleşmiş Kimlikler $\neq$ Dijital Kimlikler: Sosyal Medyada Algoritmik Filtreleme ve Benliğin Sunumunun Ticarileştirilmesi" (Corporised Identities $\neq$ Digital Identities: Algorithmic Filtering on Social Media and the Commercialisation of Presentation of Self) başlığını taşıyor. Yazar, Goffman'ın Günlük Yaşamda Benliğin Sunumu ve MacKenzie'nin Otonomi, Baskı ve Cinsiyet metinlerindeki teorilerini derinleştirerek özellikle sosyal medya platformlarında 
bireyin kimliğinin ticari manipülasyonu üzerinden özerkliğin etkilenmesini ele alıyor. Kitabın dördüncü bölümü Michael Klenk tarafindan yazılan "Dijital Refah ve Çevrim İçi Manipülasyon" (Digital Well-Being and Manipulation Online) makalesine yer veriyor. Klenk, bu makalede kendi oluşturduğu manipülasyon tanımı üzerinden sosyal medya yazılımlarının kullanıcılarla olan ilişkisini dijital refah konusu ile irtibatlı olarak değerlendiriyor. Michele Loi'nin kaleme aldığı "Felsefe Dijital Refah Çalışmalarına Ne Katkı Sağlayabilir" (What Contribution Can Philosophy Provide to Studies of Digital Well-Being) makalesi temelde refah kavramının tanımına dair bir tartışma yürütüyor. Refahın bütün bireyler için mutlak iyi ve bağlamdan bağımsız olduğu görüşünün aksine Loi'nin temel iddiası, felsefenin dijital refah çalışmalarına sağlayabileceği katkının dijital enformasyon ortamlarından etkilenen farklı durumları karşılaştırmayı ve değerlendirmeyi sağlayacak bir tanım aralığı sunmak olduğudur. Matthew D. Jennis "Dijital Refahı Geliştirmek ve Kişisel Bakım Uygulamalarının Yükselişi” (Cultivating Digital Well-Being and the Rise of Self-Care Apps) makalesinde çevrim içi zaman geçirme ile dijital refah arasındaki gerilimi konu alıyor. Ekran süresi (screentime) olarak nitelendirilen ve dijital refah ile birebir ilişkili olan bu konuyu kişisel bakım uygulamaları (self-care apps) özelinde inceliyor.

Lavinia Marin ve Sabina Roeser tarafindan yazılan, "Duygular ve Dijital Refah: Çevrim içi Tartş̧malarda Sosyal Medya Dizaynının Rasyonel Ön Yargısı" (Emotions and Digital Well-Being: The Rationalistic Bias of Social Media Design in Online Deliberations) başlıklı makalelerinde kullanıcıların düşüncelerini ifade edip tartıştıkları sosyal medya mecralarında duyguların yerini ve bunun dijital refahla olan ilişkisini konu alıyorlar. Kitaptaki sekizinci makale olan, "Kişisel Dijital Düşünceye İmkân Sağlamada Etik Zorluklar ve Yol Gösterici IIlkelere" (Ethical Challenges and Guiding Principles in Facilitating Personal Digital Reflection) başlıklı çalışmada, Andrew Gibson ve Jill Willis, kendi geliştirdikleri bir uygulama olan ve kullanıcıların kendi kişisel tecrübelerini yazıya aktarmasını ve bu tecrübeler üzerine düşünmesini hedefleyen "GoingOk" uygulamasının kurulum ve kullanım aşamalarında dijital refaha dair karşılaşttkları etik problemleri ve kendi uyguladıkları çözümleri sunuyorlar. Clement Bellet ve Paul Frijters tarafindan kaleme alınan "Büyük Veri ve Refah: Ekonomik Bir Perspektif" (Big Data and Wellbeing: An Economic Perspective) makalesi kitabın dokuzuncu bölümü olarak karşımıza çıkıyor. Yazarlar bu makalede büyük veri ve refah ilişkisini çok geniş bir çerçevede ele alıyorlar. Metnin temel problemi yapay zekâ sistemleri aracılığıyla toplanan büyük verinin toplumsal refah ile ilişkisinin nasıl anlaşılması gerektiği çerçevesinde sunuluyor. Amelia Fiske, Peter Henningsen ve Alena 
Buyx, "Bedenlenmiş Yapay Zekânın Akıl Sağlığı Hizmetinde Dijital Refah Açısından Sonuçları" (The Implications of Embodied Artificial Intelligence in Mental Healthcare for Digital Wellbeing) başlıklı makalelerinde bedenlenmiş yapay zekâ uygulamalarının psikiyatri, psikoloji ve psikoterapi sahalarında kullanılmasıyla beraber gelen genel faydaları ve kullanımlarla beraber kendisini gösteren etik problemleri analiz ediyorlar. Nick Byrd, "Sıkıntı Hâline Dair Nedensel Ağ Muhasebesi: Depresyon \& Dijital Refah" (Causal Network Accounts of Ill-Being: Depression \& Digital Well-Being) adlı makalesinde refahın nedensel ağ merkezli tanımını genelde sıkıntılı olma hâline (ill-being), özelde ise depresyon durumuna uygulayarak depresyon ve dijital teknoloji kaynaklı rahatsızlıklar üzerinden sıkıntı olma hâline dair nedensel ağlarla irtibatlı olarak bir izahat getirmeyi hedefliyor. "Hastalığın Nedensel Temeli Olarak Kötü Amaçlı Yazılımlar" (Malware as the Causal Basis of Disease) başlıklı kitabın son makalesinde ise Michael Thornton, kişilerin biyolojik sistemiyle entegreli olarak çalışan dijital kalp pili gibi cihazların bu kişilerin sağlık durumlarına karar vermede vücudun doğal bir parçası olarak kabul edilmesinin gerekliliğini tartışıyor.

Girişte de bahsedildiği üzere kitabın editörleri kitabın amacını dijital refah tartışmalarının temel üç problemi olarak ortaya koydukları dijital minnettarlık, otomatize müdahaleler ve sürdürülebilir ortak refah konuları üzerinden sunuyorlar. Bu üç başlık aynı zamanda kitaptaki makalelerin içerik olarak çerçevesini de belirleme vazifesi görüyor. Dolayısıyla kitabın hedeflediği amacı sunmasında ve tartışmasında ne kadar başarılı olduğunun tespit ve tenkit edilebilmesi bu üç temanın ifade ettikleri anlamı izah etmeyi gerektiriyor.

Yazarlar dijital minnettarlık kavramını dijital teknolojilerin ve yapay zekâ uygulamalarının insanların duyguları, ifadeleri ve insanlar arası ilişkiler üzerindeki aracı rolü olarak tanımlıyorlar. Daha basit bir ifadeyle, bu tanımlama dijital teknolojilerin bahsi geçen durumlar söz konusu olduğunda nötr bir konumda olmadığını ifade ediyor. Minnettarlık hem bireysel hem de toplumsal bazda sahip olduğumuz tasavvurların refahla olan irtibatını belirlemede merkezi bir önem teşkil eder. Bu anlamda minnettarlık, kendimize ve çevremize dair iyi olanı takdir etme ve fark etmenin bir ifadesi olarak da anlaşılabilir. Dijital teknolojilerin ve bu teknolojilerin dizaynının her geçen gün daha geniş toplumsal anlam kazandığı bir dünyada bu teknolojilerinin kuruluşunda insanlar arası ilişkilerin temelinde duran minnettarlık duygusunun ele alınması etik problemler açısından ciddi bir önem arz ediyor. Kitabın üçüncü, dördüncü ve yedinci makaleleri bu konuyla irtibatlı olan refah ve özerklik problemlerini ele alıyor.

Kitabın ikinci teması olan otomatize müdahaleler, yapay zekâ ve makine öğren- 
mesi temelli dijital teknolojilerin özellikle sağlık hizmetleri alanında doğurduğu etik ve pratik problemlere odaklanmaktadır. Bu temanın temel sorusu ise bu otomatize sistemlerin kendi başlarına yapacağı müdahalelerin hangi koşul ve şartlarda meşru olduğunu tespit etmeye dayanmaktadır. Şirketlerin finansal problemler yaşayan müşterilerini tespit etmesi, okulların kullandıkları yazılımlarla psikolojik sıkıntı yaşayan öğrencilere dair bilgi toplayıp bunları ebeveynler veya yetkili kurumlarla paylaşması veya robotik yazılımlar tarafindan verilen akıl sağlığı hizmetlerindeki belli kavram ve ifade merkezli müdahaleler gibi durumlarda kişilerin faydası, gizlilik, özerklik ve mahremiyet arasındaki hassas ilişki otomatize müdahaleleri etik bir probleme dönüştürmektedir. Bu anlamda bu problem, sosyal medya mecralarının öneri sistemlerine kadar genişletilebilir. Kişilerin davranış yapıları üzerinden hesaplamalar yapan algoritmaların sunduğu öneriler ve bu öneriler neticesinde doğan yönlendirme bu tip otomatik müdahalelerin sınırının ne olması gerektiği ile ilgili bir tartş̧ma doğurmaktadır. Kitabın son üç makalesi bu teknolojilerin sağlık hizmetlerinde kullanımı özelinde bu problemi ele almaktadır.

Kitabın üçüncü teması olan sürdürülebilir ortak refah, dijital teknolojilerinin dizaynı ve kullanımında toplumsal sorumluluğun konumuna işaret eder. Sosyal medyada yapılan bir yorum, beğenilen bir video, takip edilen bir sayfa veya kabul edilen bir öneri büyük bir veri ağının parçası olarak işleyen algoritmanın toplumsal ilişkileri belirlemesinde ve insanların yönlendirmesinde yıkıcı etkilere sahip olabilecek faaliyetlere dönüşebilirler. Dolayısıyla bu sistemlerin işleyişinde etik prensipler toplumsal refahın sürdürülebilmesinde önemli bir rol oynar. Bu anlamda yapay zekâ uygulamalarının dizaynı ve işleyişinin bu etik hassasiyet çerçevesinden tekrar incelenmesi etik bir zorunluluk olarak ortaya çıkar. Bu anlamda, sürdürülebilir toplumsal refah, bu teknolojilerin dizaynında nihai ve yönlendirici bir hedef olarak da ele alınır. Kitaptaki ikinci ve beşinci makaleler temelde bu probleme dair bir tartş̧ma yürütmektedir.

Öncelikle kitaptaki makalelerin bu üç probleme referans yaptıklarını ve bu problemlerin çeşitli uygulama alanları üzerinden ele alındığını söyleyebiliriz. Bu açıdan kitap, hedeflediği multidisipliner ve geniş konu aralığını sağlamada başarılı olarak addedilebilir. Kitap; ekonomiden sağlığa, sosyolojiden eğitime kadar birçok farklı alanda yapay zekâ uygulamalarının kullanımıyla ilişkili olarak doğan problemleri ele almaktadır. Örneğin kitabın sekizinci makalesinde otomatize müdahale, özerklik ve refah arasındaki ilişkinin bizzat yazarların kendi geliştirdikleri bir uygulamanın kullanımında karşılaştkları etik problemler ve bu probleme ürettikleri çözümler üzerinden sunulması, okuyucuya bahsi ge- 
çen problemi pratik bir mesele üzerinden anlama imkânı sağlamaktadır. Aynı şekilde kitabın altıncı makalesinde öz bakım uygulamaları, ekran süresi ve kişisel refaha dair yapılan analizde bu uygulamaların kullanımına ve kullanıcıların refah durumlarına dair verilerin sunularak tartışmanın bu veri seti üzerinden yürütülmesi okuyucuya ekran süresi gibi çok basit ve temel bir konuya dair bilgi ve farkındalık kazandırmaktadır.

Diğer yandan makalelerin genel olarak ele aldıkları örneklemelere ve bu örnekler üzerinden sundukları iddialara dair yürüttükleri teorik tartışmanın derinliğinin aynı seviyede detaylı olduğunu söylemek mümkün değildir. Refah, yapay zekâ ve insan ilişkisi, etiğin tanımı gibi kitabın anlaşılmasında oldukça önemli olan temel meseleler hakkında teorik ve tarihsel bir tartş̧manın eksik olduğu fark edilmektedir. Kitabın Loi tarafindan yazılan beşinci makalesini, özel olarak felsefenin refah tartışmasına sağlayacağı katkıya odaklanmasına rağmen analitik felsefe içerisindeki refaha dair temel aksiyomları dijital refah konusuyla ilişkilendirme hususunda zayıf kalmaktadır. Diğer yandan, örneğin kitabın dördüncü makalesinde dijital refah ve manipülasyon ilişkisi ele alınmakta, buna rağmen yazarın manipülasyona dair kurduğu teorik çerçeve ve bu çerçevenin dijital refahla olan ilişkisi büyük ölçüde havada kalmaktadır. Yazar; manipülasyonu, maniple edenin maniple edileni yönlendirdiği eylemin amaçlarını ve sebeplerini kendisine izhar etmemesi olarak tanımlayıp neredeyse bütün çevrim içi uygulamaları manipülatif olarak sınıflandırmaktadır. Fakat aynı zaman örneğin sosyal medya uygulamalarındaki öneri sisteminin işleyişinin mantığını birçok kullanıcının bildiğini ve hatta bu uygulamaların bu işleyişi kendilerinin ortaya serdiğini de ifade etmektedir. Bu örnekte de görüleceği üzere kitapta derinlemesine teorik bir tartışma bulmak kolay değildir.

Kitaptaki makalelerin kullandığı literatür, konuyu daha ileri okumalarla takip etmek isteyen okuyucular için büyük bir firsat sunmaktadır. Kitaptaki makaleler; dijital refah konusunu sağlık, eğitim, ekonomi, felsefe ve psikoloji gibi pek çok farklı alan perspektifinden işleyen temel metinleri içermektedir. Bu yanıyla her disiplinden okuyucunun kendi alanıyla ilgili temel metinleri ve hâlihazırda bu alanlarda çalışan akademisyenleri öğrenmesi de önemli bir katkı olarak görülebilir. Ayrıca, kitabın sunduğu literatürün ziyadesiyle geniş olduğu söylenebilir.

Netice olarak genel anlamda kitabın sunduğu amaç çerçevesinde dijital refah meselesine verimli bir giriş imkânı sunduğunu söylemek mümkündür. Kitaptaki makaleler, editörlerin ifade ettiği üç temel amaca göre orantılı olarak seçilerek bu konulara dair farklı disiplinlerden problemleri ve pratik örnekleri görme olanağı sağlamaktadır. Kitabın derin bir teorik tartışma sunmadığı bir gerçek olma- 
sına rağmen kitabın sunumunda belirtilen amaç göz önüne alındığında refah veya teknoloji problemlerine dair tarihsel ve derin felsefi bir tartş̧ma beklemek çok da doğru olmayacaktır. Nitekim kitaptaki felsefi tartışmalar, teorik felsefe seviyesinde değil uygulamalı etik tartş̧malar çerçevesinde değerlendirilğinde kitabın başarısına dair daha doğru bir yargıya ulaşılabilir. Bu yönleriyle kitap, henüz yeni olan ve akademide yeni yer almaya başlayan fakat önümüzdeki yıllarda daha merkezi hâle geleceği açık olan dijital refah konusu ile ilgili temel bir derleme metin olarak değerlendirilebilir. 


\section{Philosophical Studies Series}

Christopher Burr Luciano Floridi Editors

Ethics

of Digital

Well-Being

A Multidisciplinary Approach

Springer 